\title{
USING CONTINUOUS SIMULATION FOR IDENTIFYING BOTTLENECKS IN SPECIFIC OPERATION
}

\author{
Straka, M. ; Hurna, S. ${ }^{* *}$; Bozogan, M. ${ }^{* *} \&$ Spirkova, D. ${ }^{* * *}$ \\ *Institute of Logistics, BERG Faculty, Technical University of Kosice, Park Komenskeho 14, \\ 04384 Kosice, Slovakia, EU \\ *** Mendel University in Brno, Zemedelska 1, 61300 Brno, Czech Republic, EU \\ *** Slovak University of Technology in Bratislava, Vazovova 5, 81107 Bratislava, Slovakia, EU \\ E-Mail: martin.straka@tuke.sk, sona.hurna@mendelu.cz,xbozogan@mendelu.cz, \\ spirkova.daniela@gmail.com
}

\begin{abstract}
Article deals with creation of continuous simulation model of actual check-in process of selected airline based on identified decision points in passenger handling process. Case study covers actual passenger acceptance situations based on their fulfilment to ticket conditions, ticket fare, transported baggage and considering overbooking situations as planned part of airline revenue management strategy. The problem is related to the identification of bottlenecks in order to efficiently plan and use check-in counters and effectively utilize aircraft seating capacity. Case study shows importance of proper setting of check-in process, together with associated fees in case of not fulfilling ticket conditions, which helps airlines to move breakpoint to favourable percentage of load factor. Simulation models points to possibilities of restriction procedures that affects risk management and movement of breakpoint according to utilization of the aircraft and influence final revenue from the flight. The results of the computer simulation show that ticket prices range from $100.81 €$ to $398.14 €$, the luggage weights ranges from $0.06 \mathrm{~kg}$ to $31.57 \mathrm{~kg}$, the total revenue from ticket sales and baggage payments is $44125.8 €$.
\end{abstract}

(Received in February 2019, accepted in June 2019. This paper was with the authors 1 month for 2 revisions.)

Key Words: Continuous Simulation, Bottlenecks, EXTENDSIM, Service, System

\section{INTRODUCTION}

The identification of bottlenecks in the operation of different systems, both production and non-production, is one of the main priorities for ensuring their efficient operation and defining the possibilities for increasing their capacities. The problem is related to the identification of bottlenecks in order to efficiently plan and use check-in counters and effectively utilize aircraft seating capacity. The main scientific contribution of the work is a practical example of using continuous simulation to efficiently identify bottlenecks in the process of the first airline service, which is "Check in". Using appropriate simulation models, it is possible to identify bottlenecks in the system and solve the most effective system settings. This is also true for the passenger's airport system, with a focus on passengers' satisfaction and the speed of their acceptance for transport. Very interesting is the analysis of the given issue with a focus on the speed of equipment of the passengers by Hiemstra-Van Mastrigt et al. [1]. Interferences during the boarding procedure are one of the main reasons of departure delays, thereby increasing the turn-around time, and leading to higher costs. Hence, passenger boarding is becoming a relevant problem for airline companies. According to Steffen [2] efficient boarding of aircrafts is critical to ensure short turn-around times, thereby also increasing the efficiency of flight schedules, since airplanes are able to make more flying hours per day. According to Roa and $\mathrm{Hu}$ [3] demand approaches capacity at main hub airports, then is necessary have focused on safely reducing current aircraft separations, which are considered a bottleneck in the effort to increase the utilization of existing airport facilities. 
Terminal areas are becoming the bottleneck of the entire air traffic control system, in particular in the major European airports, where there is a limited possibility to build new infrastructure. The real-time problem of effectively managing aircraft operations is particularly challenging, since it is necessary to incorporate the safety regulations into the optimization model and to consider numerous performance indicators that are important to compute good quality solutions [4, 5]. According to Kim et al. [6] baggage handling systems take up a significant portion of an airport's overall operation. In particular, an entryway baggage handling systems is an essential component as it facilitates a smooth transition for baggage flowing from the check-in area to the general baggage handling systems by reconstituting a dynamic baggage flow into a stable flow on a conveyor system.

The use of simulation modelling as a scientific method in research and in practice is very widespread. The benefits that stem from the use of a simulation modelling approach include financial, time, material and energy savings as well as the streamlining of activities in practice. Simulation is therefore widely applied in various industries and areas, such as education, health, information technology and robotics, economics, business, logistics and transport services [7-10]. A continuous simulation - the values of state variables are changing continuously in a given time interval. Value is determined variables are determined by solving differential equations that describe the behaviour of the simulated the system in a very short time steps $[11,12]$. The process simulation models are very efficient tools for detecting the bottlenecks in the process course and for improving the process parameters. Neither costs nor negative impacts are connected with interfering in a simulation model of a production line, unlike to interfering in the operation of this line. To develop the proper simulation model, both theoretical knowledge (technique of simulation, specific simulation systems) and practical experience (description of the system, its elements and their mutual interactions and links) are necessary [13-15]. For design of simulation models is possible to use a several simulation platforms for example strategic planning for airport design and operations is a challenging task, since it should consider a variety of alternative futures, their consequences for airport performance and possible strategies for ensuring that the airport meets its business objectives. Existing models and tools for quantifying airport performance require significant detailed data, substantial airport modelling effort and do not readily produce the information relevant to decision makers [16]. According to Scala et al. [17] airport capacity, expressed as the maximum number of air traffic movements that can be accommodated during a given period of time under given conditions, has become a strict constraint to the air transportation, due to the scarce amount of resources on the ground and restrictions in the airspace. Simulation model is developing that takes into account both airspace and ground operations. This integrated approach allows assessing the system as a whole, identifying possible bottlenecks and elements that affect the real system [18]. Designing and testing complex simulation models for such systems is more demanding both in terms of system analysis and initial data collection for the design of models and in terms of verification of the models and validation of the results in practice [19].

Evaluation of landside capacity by means of simulation enables airport operators and airport designers to identify passenger and baggage flow bottlenecks, identify the primary cause of bottlenecks formation and take measures mitigating the impact of bottlenecks on the airport terminal operation [20-22]. In generally the simulation model is defined by a specific sequence of modelling blocks connected by lines representing the processing flow directions. The block position, icon and name, the connector blocks, the links as well as the user interface dialogues with operands and flows are the main properties of individual blocks [23]. The main objective of the paper is to highlight the possibility of continuous simulation of the EXTENDSIM simulation system for the identification of bottlenecks in the air traffic logistics environment. The basic change in the creation of the simulation model itself stems from the 
perspective of passengers, luggage and the sale of travel tickets. Passengers within our model are not represented as a unit, a piece that passes through the whole model, but are represented as a random serial numbers with a random number generator, to which other random numbers refer to the size of the luggage and the price of the ticket. The given point of view from the principle side to the model itself is interesting, innovative and inspiring for other cases of simulation modelling.

\section{METHODOLOGICAL BASE}

In order to be able to compile a computer simulation model to identify a breaking point of passenger air traffic in a particular airline, a rigorous analysis of its operation needs to be developed and implemented. The activity is typical for most airlines providing passenger services. For the compilation of the model, it is necessary to describe the whole process from the arrival of the passenger to the airport, to the actual transport. The passenger arrives at the airport to enter the boarding zone through the area called "Check in". Within the given operation, the allowance of the baggage, the validity of the ticket, personal documents, etc. are checked. Some airports have check in process where passengers can check in their bags to an airline representative before entering the terminal and then proceed directly to the security check [24-26]. In simulation models, it is necessary to consider, and thus imitate, situations, when passengers who have a paid and valid ticket, do not carry out the check-in operation for objective or subjective reasons and, therefore, do not board the aircraft. Depending on the type of ticket or conditions of transport, it is decided whether part of the fare, full fare or just unused taxes are returned. The main activity of airline companies is transport of passengers. Thus, the main activities are also related to side-related activities, which are associated with passenger comfort, baggage transportation and manipulation, handling, meals (food, beverage on board or drinks only), and the like. The expanded service offer allows for increased price elasticity and differentiation of flight fares for the transport process. Airlines follow various pricing strategies. The closer the date of departure is, the higher is the price of a given flight. The carriers may set different prices depending on the number of days between departure and arrival and depending on the date of purchase [27-30].

From the system analysis of passenger transport, and the activity of the airline, the following findings arise:

- There is a change in charges for services related to the carriage of persons and their accessories.

- As the airline ticket sales, using secondary statistics, are planned to be over-the-capacity so called „Overbooking“, there are situations where a certain seat on the aircraft has more than one passenger assigned, therefore, few passengers must be offered an alternative flight or alternative means of transport. Airlines typically explain their practices as being motivated by the fact that a certain number of passengers can be expected not to show up (on time) for a flight and overbooking capitalizes on slack capacity, improving efficiency [31].

- There is considerable variability in the process of flight price development due to supply and demand, as well as a change in the philosophy of their sales.

- Variability of ticket pricing positively influences the growth of interest in flights to some destinations, which may also be an inspiration for other forms of transport or selling services as such.

The above described implies that use of a computerized continuous simulation is a convenient mean of comparing the real state with possible states that can occur at defined intervals. The input parameter and intervals for setting the continuous simulation model were defined statistically from real operations. 


\section{CASE STUDY}

Airline business, airline ticket sales and passenger acceptance have their system and exact sequence. From the above information and after the activity analysis, it is possible to construct a formalized scheme for the implementation of pre-flight operations, related to the acceptance of passengers on board an aircraft. The formalized scheme represents the overall system with its elements and bonds. The elements of the system are individual parts and operations related to the passengers' acceptance on board of the aircraft, respectively, nonarrival of the passenger to check-in area and therefore denial of transportation service. Between operations, bonds are created of transport elements and the management of passenger acceptance in relation to passenger activities in the "Check in" area. In scope of the reviewed system, the main purpose is to monitor the number of passengers served at different ticket price levels, using restrictive, semi-restrictive and unrestrictive tariffs, and identifying the breakpoint for cost-efficient and profitable passenger air transport, which is of course the long-term goal of each airline.

\subsection{A formalized scheme and block diagram of the new personal air transport tariff system}

The constructed formalized scheme forms (see Fig. 1) an important basis for the creation of the simulation model itself. The individual parts of the formalized scheme are successively replaced by the respective blocks of a particular simulation system. The creation of the simulation model consists of two parts. The first part is represented by the block diagram of the respective simulation system (see Fig. 2) and the second part is the simulation model itself with the research for the investigated area of passenger air transport (see Fig. 3).

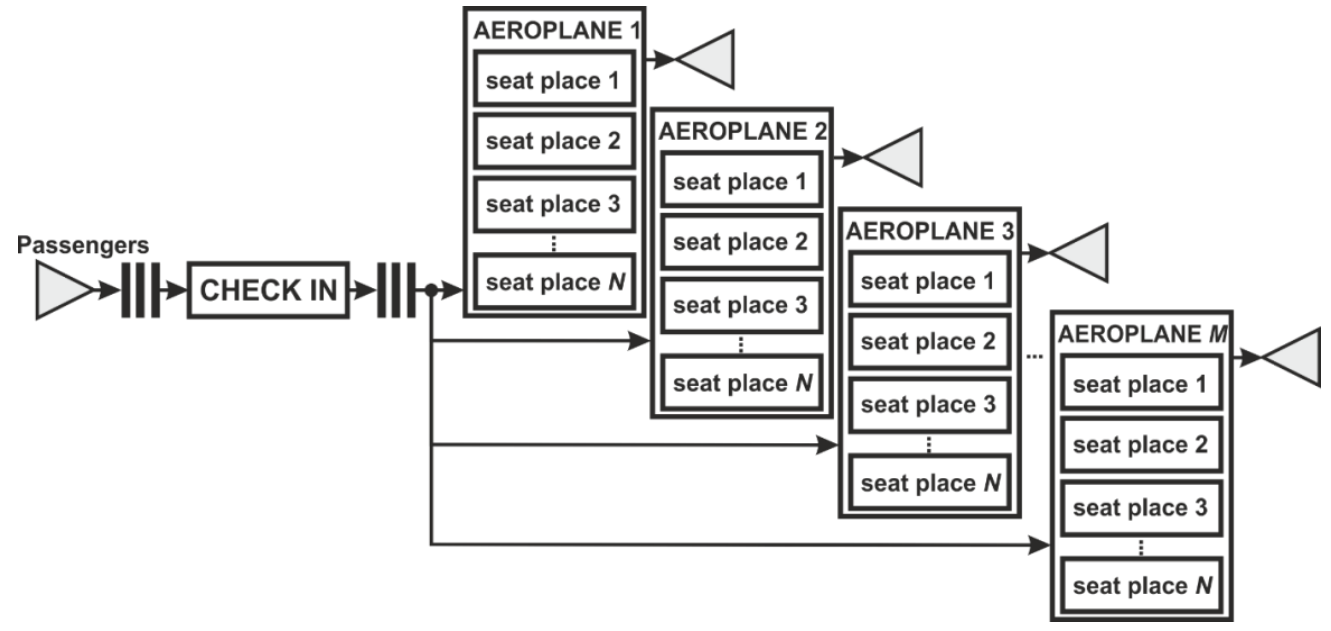

Figure 1: Formalized scheme of the air passenger acceptance operations.

Constructing a block diagram as a basis for the simulation model itself is important for data and information preparation, which is important for setting the individual blocks of the simulation model. The overall operation of the system related to the identification of the number of passengers accepted for the purposes of passenger air transport will be represented by a continuous simulation model. The statistical data obtained from the activity of a particular airline indicates that the passenger arrival and the finalization of the check-in operation is pre-determined by ticket sales, but this does not guarantee that the passenger arrives at the airport and successfully completes the check-in operation. So, there is still some uncertainty that can be eliminated by oversales (overbooking). At the same time, it eliminates losses in the case of the use of aircraft with a higher seat capacity etc. What cannot be 
eliminated is the state of the luggage of the passengers. The weight of the luggage and how many pieces it will consist of is clear at the moment of the check-in process and at the direct contact of the prospective passenger during the "Check in" steps. Once the input parameters have been identified, the total cost of the services provided for each passenger can be adjusted separately. This implies that there are a number of factors affecting the total cost of transport, which also relate to departure and arrival times and other factors.

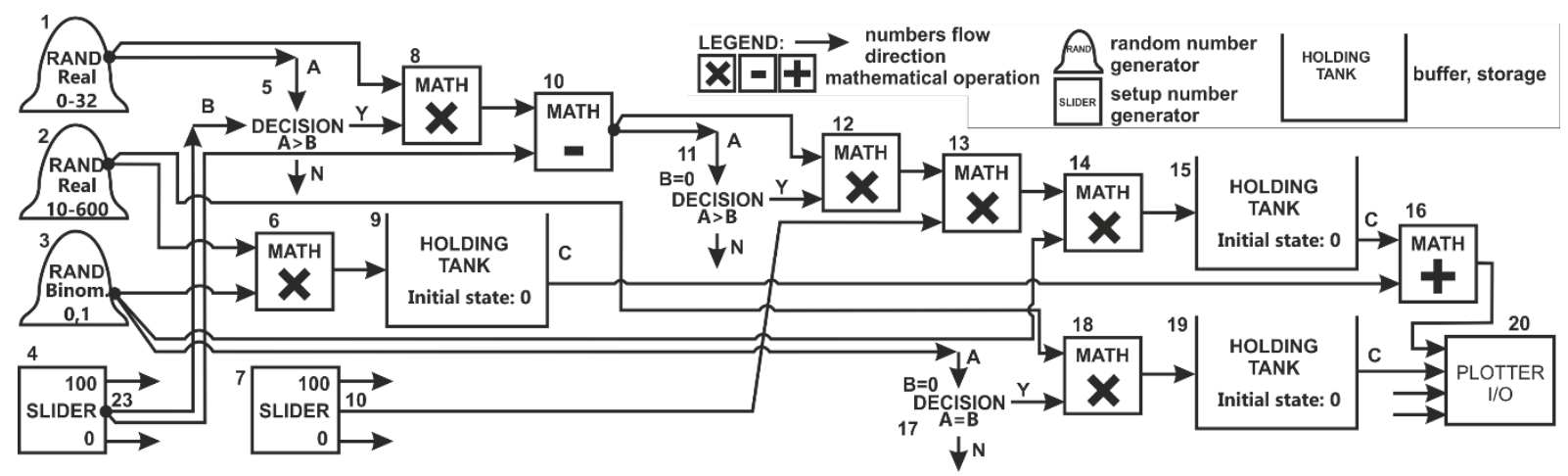

Figure 2: Block diagram of the EXTENDSIM continuous simulation system for identifying the breakpoint in passenger air traffic.

Generally, it is possible to state that the weight of the luggage is a random parameter and can range from 0 to $32 \mathrm{~kg}$ per piece of luggage (over $32 \mathrm{~kg}$ is already a cargo transport). The state of the luggage delivery and its identification within the simulation model will be represented by the "Random number" block, with distribution "Real Uniform 0-32". Another important parameter that changes over time is the ticket price. Ticket prices have changed from "last tickets are cheapest" to "tickets have exactly defined price for concrete time". The change in ticket pricing philosophy has lowered the pressure on the last possible time of ticket sales, allowing companies to provide ahead of time with sufficient precision the necessary indirect elements related to passenger comfort. Within the simulation model, the ticket price is represented by the "Random number" block, respectively "Lookup Table" where the ticket price is based on well-defined criteria. Another parameter with probability of occurrence is the condition if the client, who has purchased ticket, arrives at "Check in" or for some reason does not finalize the operation. Statistically, the state where the customer does not show for departure is up to $10 \%$. In simulation models, the given state is represented by a "Random number" block with a "Binomial" distribution, interval 0-1 and probability 0.9 ".

Other parts of the continuous simulation model are represented by mathematical operations - blocks "Math", decision blocks - „Decision", and accumulation of values blocks - "Holding Tank".

\subsection{Continuous simulation model design of the new personal air transport tariff system}

The prepared block diagram of the Passenger Acceptance Model represents an inactive part of the computer simulation model itself. The following is a block diagram implementation in a particular simulation system, whereby an inactive computer simulation model becomes an inactive part with which to conduct research. The result of the active part of the simulation model implementation is the data that represents the activity of the passenger's acceptance through the "Check in" process of their accidental states, which allows the breakpoint to be examined under different terms and conditions.

The simulation model consists of blocks (see Fig. 3), which represent the individual monitored parts. Each block of the simulation model has its meaning and justification. Not all operations can be modelled by one block, but several blocks must be used in a sequence that 
corresponds to the actual operation of the passenger's acceptance process. No less important part of the whole simulation model is the consistent setting of the simulation model parameters as follows from the analysis, formalized and block diagram.

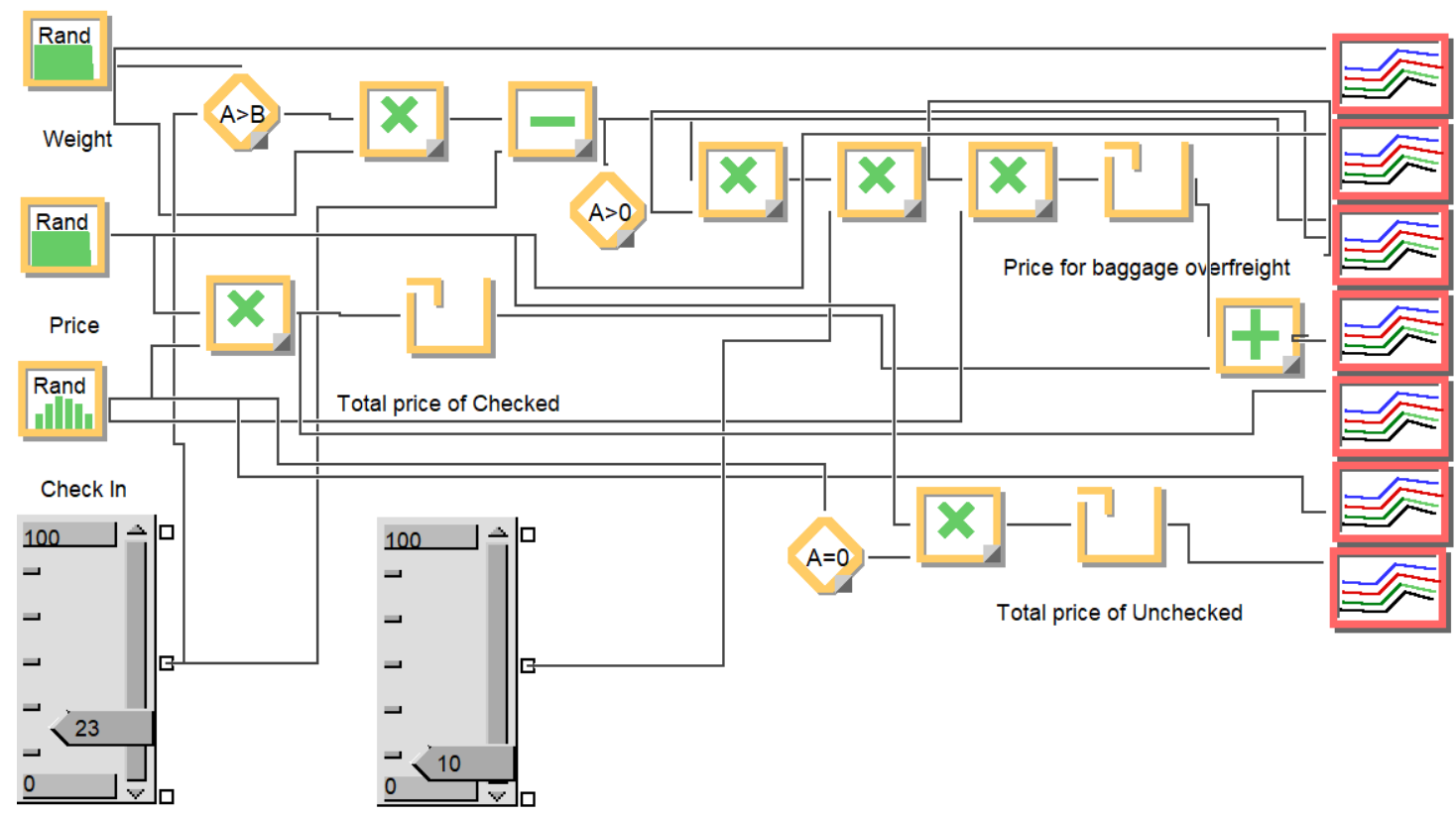

Figure 3: The simulation model of passenger acceptance through "Check in" by EXTENDSIM.

Parts of the simulation model are characterized by a sequence of blocks that are joined by lines that uniquely determine the flow direction. The basic characteristics of each model block are defined by the location, block icon and block name, block connectors, connectors, operand dialogs, and flows.

Each block used occupies a certain location, a position in the simulation model that represents a real-world system. The blocks themselves represent certain parts of the processes or systems from which the actual real-system model is created.

Icons and block names are block images with their exact unique name that describe their basic function. Each block has its unique icon and its unique name, which expresses its basic use within the models. The "Random Number" block is a random number generator that represents the random statuses associated with each potential passenger individually, such as luggage weight, ticket price, or customer boarding the aircraft and therefore successfully implements the "Check in". The Holding Tank block identifies the number of passengers accepted, excess baggage fees and unchecked customer information.

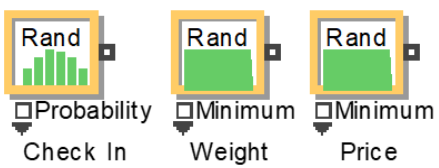

Figure 4: "Random Number" blocks, which represent the random arrival status of the passengers, the weight of the luggage and the associated ticket price.

The "Random Number" block (see Fig. 4) must be used to ensure the random status of the luggage of the passengers arriving at "Check in" and set the distribution function to "Uniform Real" with a range of 0-32. The given setting for each passenger generates his luggage weight (see Fig. 5). It has been statistically found that around $10 \%$ of passengers with a purchased ticket do not board a plane. To ensure the random state of the "Check in" of passengers, use the "Random Number" block and set the distribution function to "Binomial" with a value of 0.1 and a probability of state 1 of 0.9 , representing $90 \%$ of the passengers accepted. This 
setting represents only two states "yes-no, 0-1, true-false," i.e. the traveller commences or does not commence the journey with a defined probability (see Fig. 6).

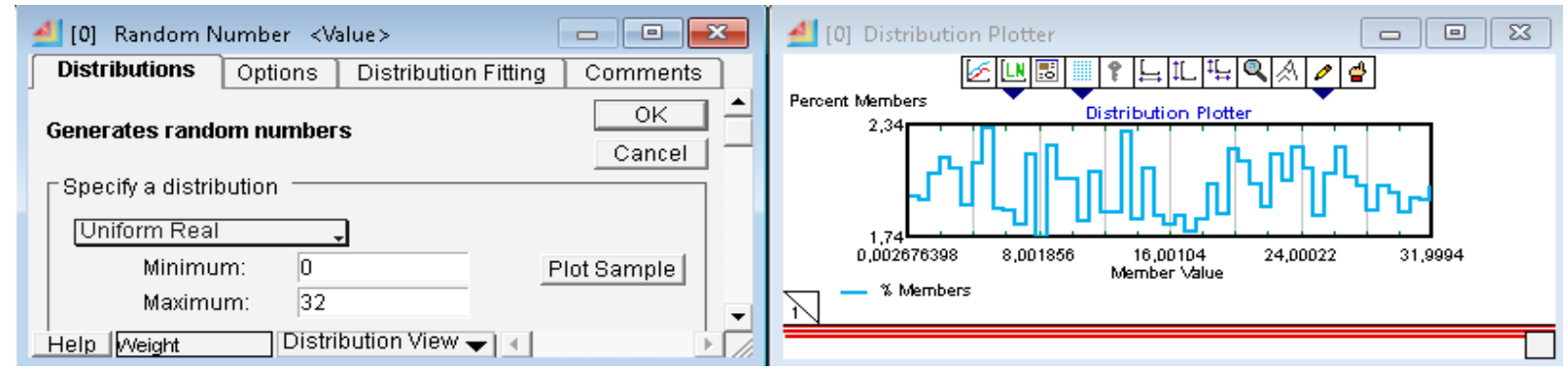

Figure 5: Dialogue block "Random Number" and the setting for the purpose of generating the weight of baggage.

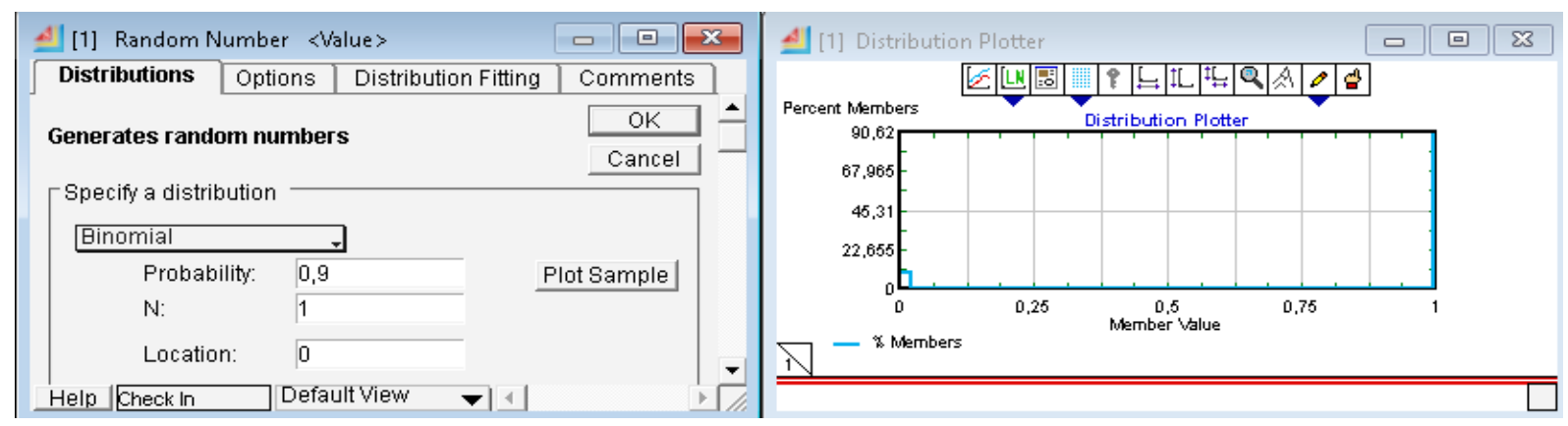

Figure 6: Random Number block dialog and its setting for "Check in".

In simulation model, ticket pricing can be captured in two ways. Either as a random state, as it is not possible to know beforehand when the passenger enters the system and orders the ticket, or as a random status in terms of time but with the exact number of tickets sold and at the relevant price. To simulate a given state, you can use the "Random Number" block and set the distribution function to "Uniform Real" with a range of 100-400. The given setting for each passenger generates his ticket price (see Fig. 7).

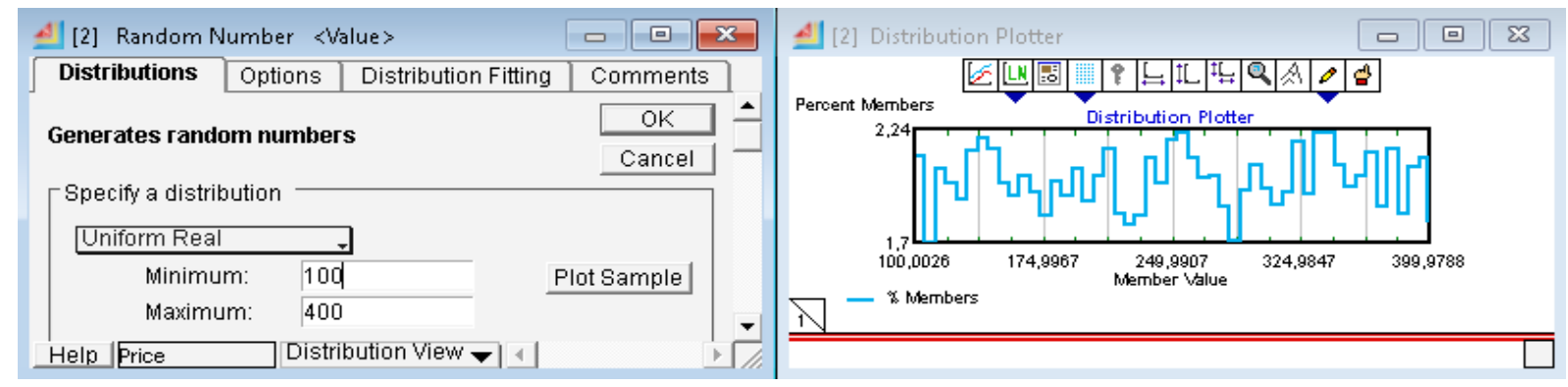

Figure 7: Dialog block "Random Number" and the setting for the purpose of generating ticket prices.

Within the simulation model, the same decisions need to be made as they are in practice. Decisions are expressed in "0-1" and relate to the following questions: "Does the weight of the luggage correspond to the transport conditions?" Did a passenger passed "Check in" successfully?" (see Fig. 8).

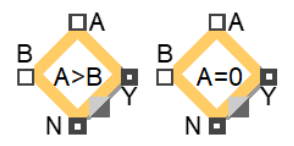

Figure 8: "Decision" blocks representing decisions on the correctness of the luggage weight and the "Check in" execution. 
The activity of the "Decision" block within the simulation model is given by the input parameters, where two incoming values are compared and, within the defined condition, the decision becomes either true or false. If the condition is true, the block sends a value of 1 to the connector " $\mathrm{Y}$ " and a value of 0 for the connector " $\mathrm{N}$ " and if the condition is incorrectly evaluated, the block sends 0 to the "Y" connector and the value "1" to the "N" connector (see Fig. 9).

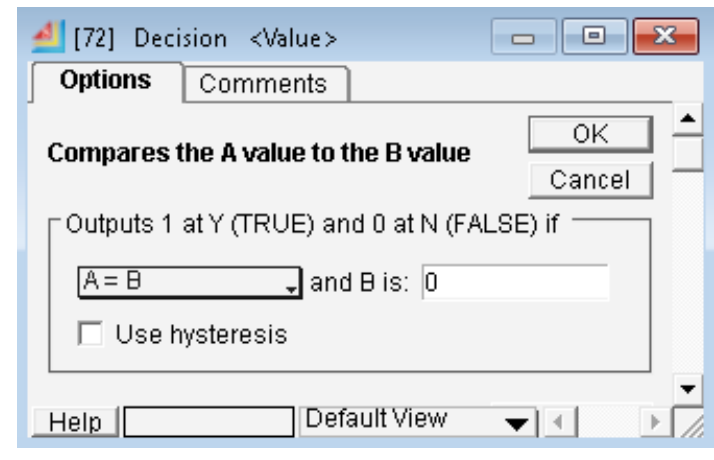

Figure 9: The "Decision" block dialog and its setting.

"Holding Tank" blocks (see Fig. 10) serve to accumulate the individual components that make up the total amount paid by the passenger for their transport.

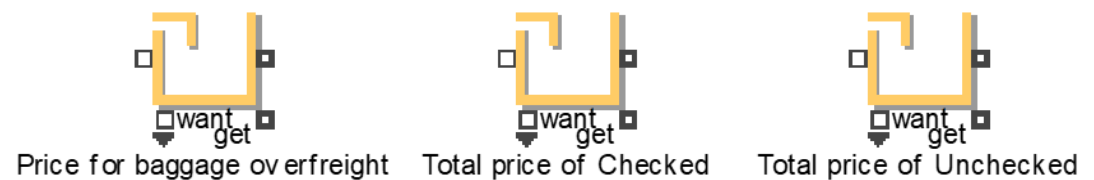

Figure 10: "Holding Tank" blocks represent tracking the sums of costs associated with the execution of "Check in" and the acceptance of passengers.

The "Holding Tank" block action can be compared to the stack where the numbers are added and the resulting value is sent to the output connector of the block while the last accumulated value remains stored in the block memory.

\section{RESULTS AND CONCLUSION}

Once the simulation model has been created and set up, it is used to examine Passenger revenue activity and their passage through the "Check in" process and their subsequent transport in a particular airline. The results of the simulation, focusing on the weight of passengers' luggage (see Fig. 11), show a span of $0.06 \mathrm{~kg}$ to $31.57 \mathrm{~kg}$.

The simulation results, focusing on passenger ticket prices (see Fig. 12), indicate a span of $100.81 €$ to $398.14 €$ per ticket. 180 seats in the aircraft were considered and the purchase of tickets for each transport location was defined as random process depending on time and price range. Simulation results with a focus on the total revenue from ticket sales and baggage payments (see Fig. 13).

Case study points to amount of variations in passenger acceptance process which allows airlines to effectively fulfil demand and supply in air transportation process and thus lower the risk of loss during the process. The results obtained by computer simulation correspond to real states that can occur in defined limits and were compared with real operation of specific airline at Kosice International Airport. 


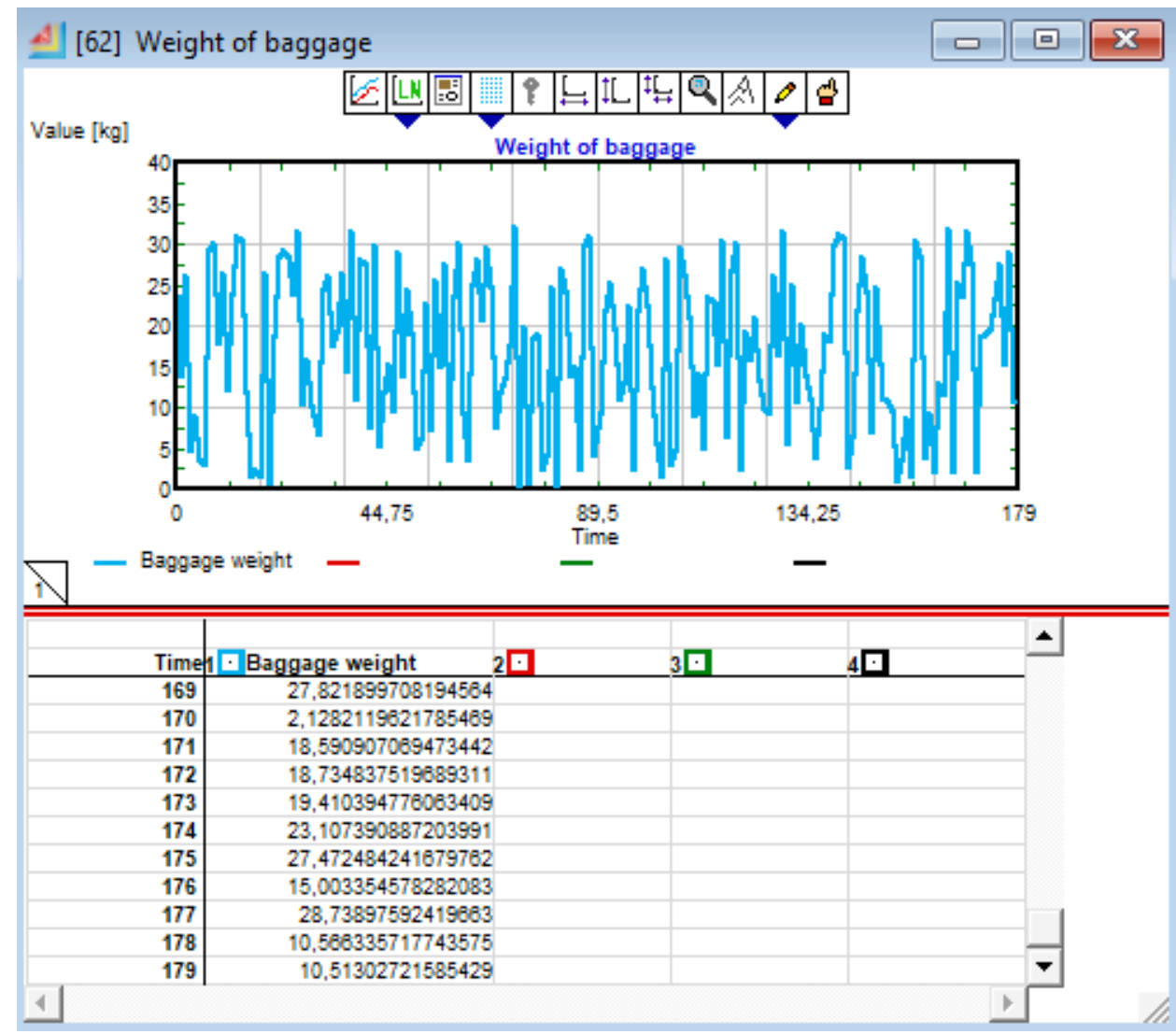

Figure 11: Results from simulation model with orientation on baggage weight.

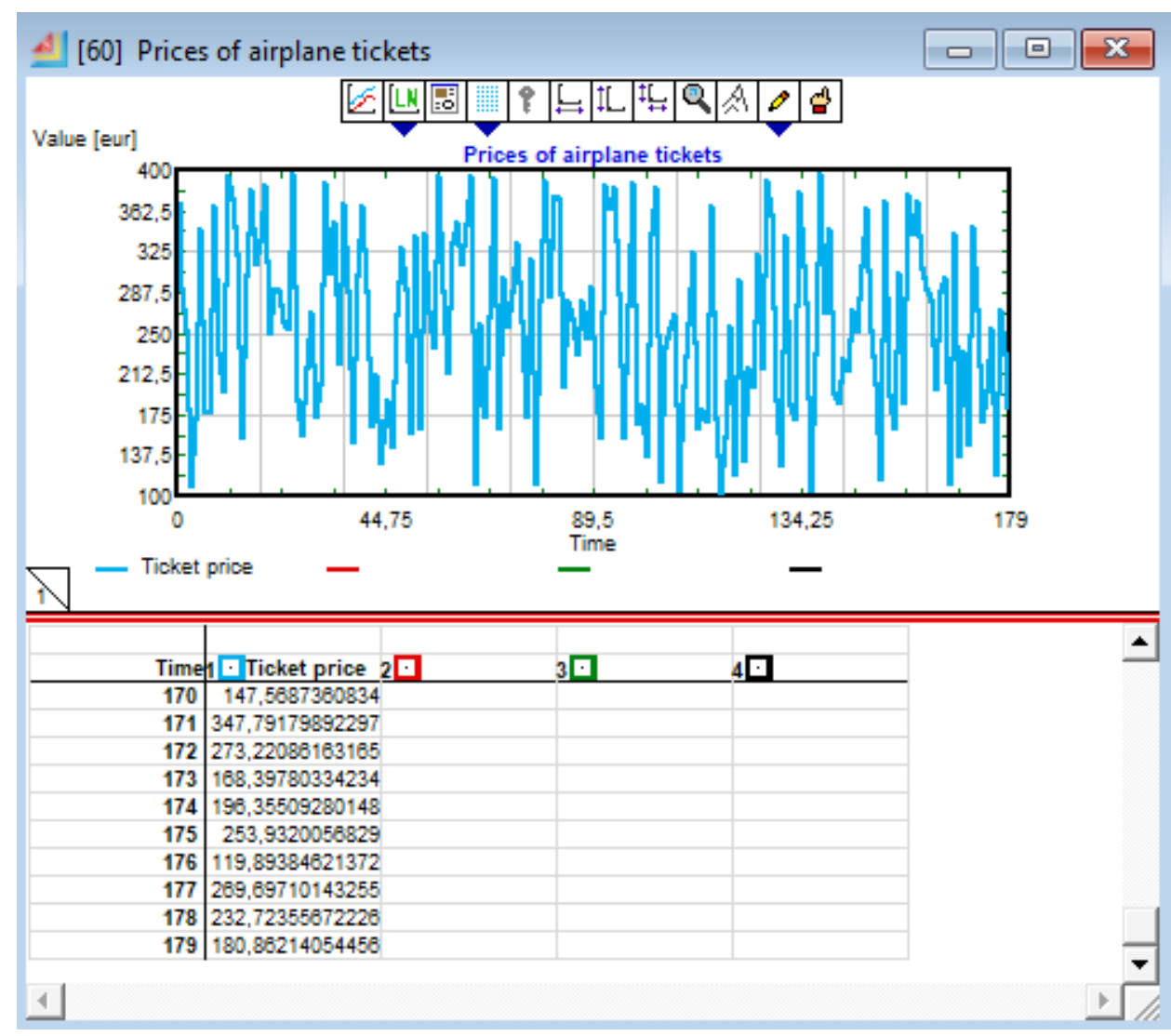

Figure 12: Simulation results with a focus on ticket price. 


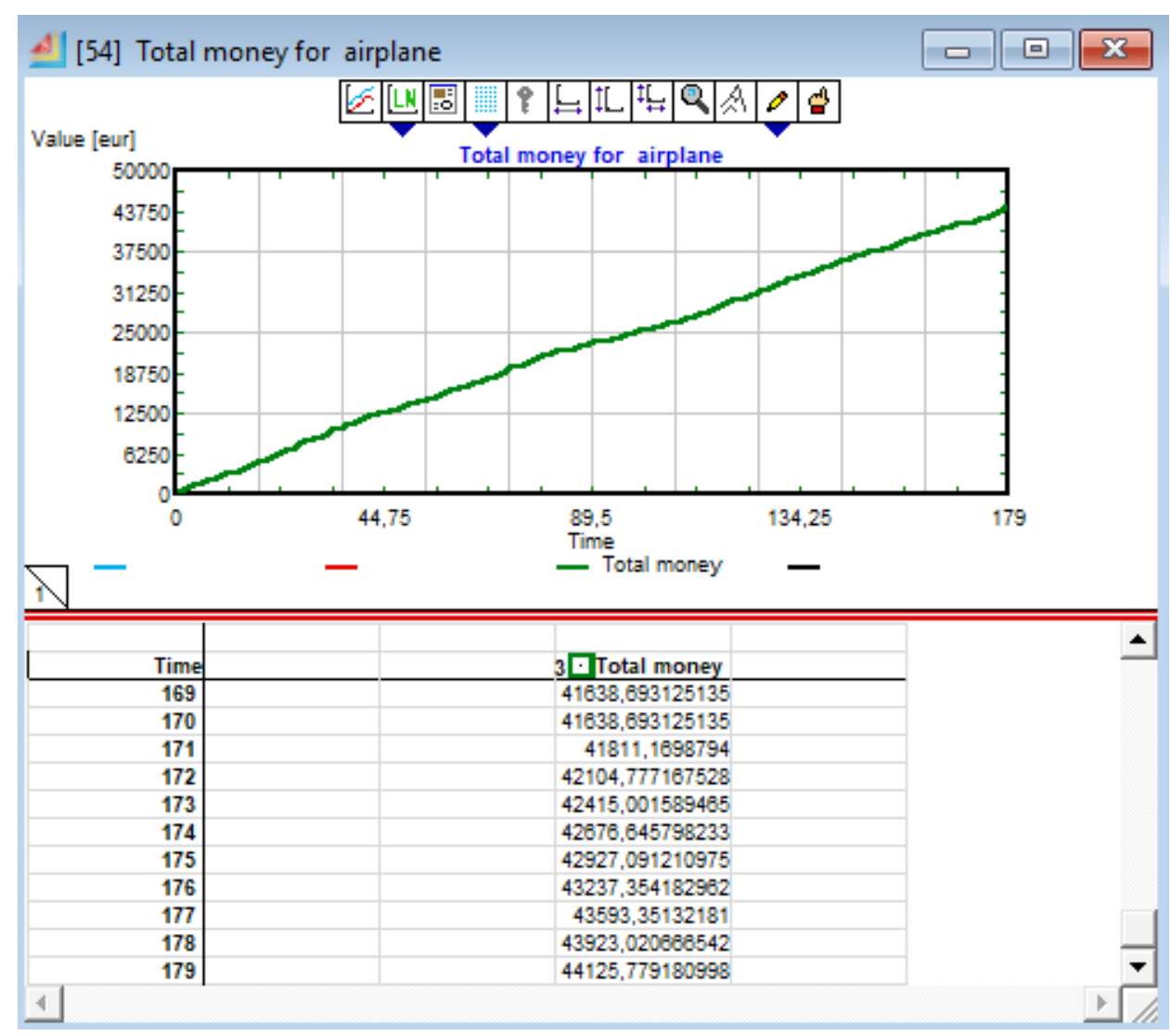

Figure 13: Results from simulation model with focus on total revenue management.

Research benefits can be defined in several areas:

- pointing out the possibility of creating continuous simulation models for air transport particularly with EXTENDSIM simulation system,

- identification of bottlenecks in a transport-oriented process,

- the impact of the variables taken on total revenue management,

- statistical determination of parameters for calculation of overbooking depending on the aircraft's free capacity.

Simulation model points to effective use of capacity of the aircraft, which later affects breakpoint of selected flight and thus price creation based on utilization and associated additional fees from passenger acceptance process. Simulation model points to dependency of selected processes, thus showing that some of the actions cannot be done without previous successful completion of prerequisite action. Application of model highly depends on passenger's behaviour, which sometimes cannot be directly influenced or assumed by the airlines. Preventive behaviour includes the effects of loping management and defence management, which might cause customer to decide not to fly at all if any feeling of danger arise [32]. This creates additional risk for the airline, which cannot be fully eliminated by additional restrictions; however, there is a possibility of risk reduction in form of statistical predictions such as implementation of overbooking policy on flights.

Further research options can be directed towards market fluctuations in the area, further development of low-cost airline companies with focus on researching hybrid revenue models and their impact on revenue management and possibility for use of EXTENDSIM simulation software in other aviation specific operation such as load planning. 


\section{ACKNOWLEDGEMENT}

The submitted paper is a part of the research projects VEGA 1/0317/19, funded by the Scientific Grant Agency of the Ministry of Education, science, research and sport of the Slovak Republic and the Slovak Academy of Sciences and PEF_DP_2019019 "Outsourcing and offshoring as tools of the growth of competitiveness of aviation companies in Central and Eastern European countries" by Internal Grant Agency of Mendel University in Brno, Czech Republic.

\section{REFERENCES}

[1] Hiemstra-Van Mastrigt, S.; Ottens, R.; Vink, P. (2019). Identifying bottlenecks and designing ideas and solutions for improving aircraft passengers' experience during boarding and disembarking, Applied Ergonomics, Vol. 77, 16-21, doi:10.1016/j.apergo.2018.12.016

[2] Steffen, J. H. (2008). Optimal boarding method for airline passengers, Journal of Air Transport Management, Vol. 14, No. 3, 146-150, doi:10.1016/j.jairtraman.2008.03.003

[3] Roa, J.; Hu, J. (2018). Modelling of runway infrastructure operations in an effort to increase economic and environmental sustainable development, Proceedings of the AHFE 2018: Advances in Human Factors, Sustainable Urban Planning and Infrastructure, 90-99, doi:10.1007/978-3-319-94199-8 9

[4] Samà, M.; D'Ariano, A.; D'Ariano, P.; Pacciarelli, D. (2017). Scheduling models for optimal aircraft traffic control at busy airports: Tardiness, priorities, equity and violations considerations, Omega, Vol. 67, 81-98, doi:10.1016/j.omega.2016.04.003

[5] Ma, J.; Delahaye, D.; Sbihi, M.; Scala, P.; Mujica Mota, M. A. (2019). Integrated optimization of terminal maneuvering area and airport at the macroscopic level, Transportation Research Part C: Emerging Technologies, Vol. 98, 338-357, doi:10.1016/j.trc.2018.12.006

[6] Kim, G.; Kim, J.; Chae, J. (2017). Balancing the baggage handling performance of a check-in area shared by multiple airlines, Journal of Air Transport Management, Vol. 58, 31-49, doi:10.1016/j.jairtraman.2016.08.017

[7] Straka, M.; Malindzakova, M.; Trebuna, P.; Rosova, A.; Pekarcikova, M.; Fill, M. (2017). Application of EXTENDSIM for improvement of production logistics' efficiency, International Journal of Simulation Modelling, Vol. 16, No. 3, 422-434, doi:10.2507/IJSIMM16(3)5.384

[8] Cheba, K.; Kiba-Janiak, M.; Saniuk, S.; Witkowski, K. (2014). Modeling transportation preferences of urban residents: The case of Poland, Proceedings of the $1^{\text {st }}$ International Summit on Internet of Things, 78-83, doi:10.1007/978-3-319-19743-2_12

[9] Delgado Sobrino, D. R.; Koštál, P.; Cagáňová, D.; Čambál, M. (2013). On the possibilities of intelligence implementation in manufacturing the role of simulation, Applied Mechanics and Materials, Vol. 309, 96-104, doi:10.4028/www.scientific.net/AMM.309.96

[10] Loučanová, E.; Parobek, J.; Paluš, H.; Kalamárová, M. (2016). Logistics as a part of innovation process, Acta logistica, Vol. 3, No. 1, 1-4, doi:10.22306/al.v3i1.56

[11] Kliment, M.; Trebuňa, P. (2014). Simulation as an appropriate way of verifying the efficiency of production variants in the design of production and non-production systems, Acta logistica, Vol. 1, No. 4, 17-21, doi:10.22306/al.v1i4.27

[12] Malindzak, D. (2010). Modely a simulacia v logistike (Models and simulation in logistics), Acta Montanistica Slovaca, Vol. 15, Special Issue 1, 1-3

[13] Straka, M.; Trebuna, P.; Rosova, A.; Malindzakova, M.; Makysova, H. (2016). Simulation of the process for production of plastics films as a way to increase the competitiveness of the company, Przemysl Chemiczny, Vol. 95, No. 1, 37-41, doi:10.15199/62.2016.1.3

[14] Knapcíková, L.; Dupláková, D.; Radchenko, S.; Hatala, M. (2017). Rheological behaviour modelling of composite materials used in engineering industry, TEM Journal, Vol. 6, No. 2, 242 245, doi:10.18421/TEM62-07

[15] Wang, Y. R.; Chen, A. N. (2016). Production logistics simulation and optimization of industrial enterprise based on Flexsim, International Journal of Simulation Modelling, Vol. 15, No. 4, $732-$ 741, doi:10.2507/IJSIMM15(4)CO18 
[16] Chen, X.; Li, J.-H.; Gao, Q. (2015). A simple process simulation model for strategic planning on the airside of an airport: A case study, Journal of Simulation, Vol. 9, No. 1, 64-72, doi: $10.1057 /$ jos.2014.20

[17] Scala, P.; Mujica, M.; De Bock, N. (2015). Modular approach for modelling an airport system, Proceedings of the $27^{\text {th }}$ European Modeling and Simulation Symposium, 21-23

[18] Danyang, S. (2013). Simulation of air cargo operations in west PACTL, Information Technology Journal, Vol. 12, No. 15, 3179-3183, doi:10.3923/itj.2013.3179.3183

[19] Straka, M.; Lenort, R.; Khouri, S.; Feliks, J. (2018). Design of large-scale logistics systems using computer simulation hierarchic structure, International Journal of Simulation Modelling, Vol. 17, No. 1, 105-118, doi:10.2507/IJSIMM17(1)422

[20] Zhang, X.; Wang, C. (2009). The airfield system capacity evaluation and delay analysis based on Simmod simulation, Proceedings of the $8^{\text {th }}$ International Conference on Chinese Logistics and Transportation Professionals, 3510-3518, doi:10.1061/40996(330)515

[21] Stefanik, M.; Badanik, B.; Matas, M. (2012). Aspects of airport ground access/egress systems, Proceedings of the 2012 Industrial Conference on Industrial Logistics, 17-29

[22] Pinon, O.; Mavris, D.; Garcia, E. (2008). A methodological approach for airport technology evaluation and selection, Proceedings of the $26^{\text {th }}$ International Congress of the Aeronautical Sciences (ICAS) and $8^{\text {th }}$ AIAA ATIO, Paper 8965, doi:10.2514/6.2008-8965

[23] Straka, M.; Malindzakova, M.; Rosova, A.; Trebuna, P. (2016). The simulation model of the material flow of municipal waste recovery, Przemysl Chemiczny, Vol. 95, No. 4, 773-777, doi: $10.15199 / 62.2016 .4 .12$

[24] Červinka, M.; Štverková, H. (2014). The operational performance and quality aspects of passenger check-in process at regional airports, Logistics and Transport, Vol. 22, 29-35

[25] Eboli, L.; Mazzulla, G. (2009). An ordinal logistic regression model for analysing airport passenger satisfaction, EuroMed Journal of Business, Vol. 4, No. 1, 40-57, doi: $10.1108 / 14502190910956684$

[26] Asrah, N. M.; Djauhari, M. A. (2012). Malaysia commercial flight passengers' safety (NEWS), Proceedings of the 2012 International Conference on Statistics in Science, Business and Engineering, 478-481, doi:10.1109/ICSSBE.2012.6396611

[27] Szopiński, T. S.; Nowacki, R. (2015). The influence of purchase date and flight duration over the dispersion of airline ticket prices, Contemporary Economics, Vol. 9, No. 3, 253-366, doi:10.5709/ce.1897-9254.174

[28] Clemons, E. K.; Hann, I.-H.; Hitt, L. M. (2002). Price dispersion and differentiation in online travel: An empirical investigation, Management Science, Vol. 48, No. 4, 534-549, doi: $10.1287 / \mathrm{mnsc} .48 .4 .534$

[29] Chellappa, R. K.; Sin, R. G.; Siddarth, S. (2011). Price formats as a source of price dispersion: A study of online and offline prices in the domestic U.S. airline markets, Information Systems Research, Vol. 22, No. 1, 83-98, doi:10.1287/isre.1090.0264

[30] De Roos, N.; Mills, G.; Whelan, S. (2010). Pricing dynamics in the Australian airline market, Economic Record, Vol. 86, No. 275, 545-562, doi:10.1111/j.1475-4932.2010.00653.x

[31] Ely, J. C.; Garrett, D. F.; Hinnosaar, T. (2017). Overbooking, Journal of the European Economic Association, Vol. 15, No. 6, 1258-1301, doi:10.1093/jeea/jvw025

[32] Bozogáňová, M. (2018). Perceived Safety and its Socio-psychological Contexts (Vnímané Bezpečie a Jeho sociálno-psychologické Kontexty), Wolters Kluwer, Bratislava 